http:/ / dx.doi.org/10.21707/gs.v11.n02a016

\title{
Percepção sobre os macrofungos em uma comunidade rural na CaAtinga, Nordeste do Brasil
}

\section{Santina Barbosa de Sousa ${ }^{1 *}$, José de Ribamar de Sousa Rocha ${ }^{1,2}$, Reinaldo Farias Paiva Lucena ${ }^{3}$, Roseli Farias Melo de Barros ${ }^{1,2}$}

\author{
${ }^{1}$ Discente do Programa de Pós-Graduação em Desenvolvimento e Meio Ambiente (PRODEMA), Núcleo de Referência em Ciências Ambientais do Trópico \\ Ecotonal do Nordeste (TROPEN), Universidade Federal do Piauí. \\ ${ }^{2}$ Docente do departamento de Biologia, Centro de Ciências Naturais, Universidade Federal do Piaui \\ ${ }^{3}$ Docente do departamento de Sistemática e Ecologia, Centro de Ciências Exatas e da Natureza, Universidade Federal da Paraíba \\ *Autor para correspondência: sbarbosadesousa@gmail.com
}

Recebido em 12 de novembro de 2015. Aceito em 14 de setembro de 2016. Publicado em 29 de julho de 2017.

\begin{abstract}
RESUmo - A percepção do homem para com os macrofungos ocorre por meio das cores, formas e ação no meio, despertando curiosidades e o interesse por eles. Dessa forma, objetivou-se compreender como uma comunidade rural manifesta os fenômenos observados dos macrofungos conhecidos/usados, com base em suas experiências particulares e a manutenção do conhecimento pela transmissão intergeracional dos saberes. Utilizou-se entrevista semiestrutura acompanhada de álbum seriado de fotografias com 56 informantes da comunidade Novo Zabelê, seguida de turnê-guiada. A percepção está relacionada com surgimento no ambiente, sazonalidade, utilização lúdica e medicinal, condição climática e função ecológica. A maioria (91\%) retrata a infância como início do conhecimento sobre os fungos, onde a família contribuiu para obtenção dos saberes, por meio da tradição oral quanto aos nomes vernaculares e função na natureza, sendo transmitido intergeracionalmente, onde a percepção negativa foi expressa pela afirmação de que fazem mal para saúde ou não são uteis e a positiva com atribuição de importância para natureza e uso na medicinal popular. Os dados reforçam que a percepção sobre os fungos é constituída culturalmente e, podem contribuir para o conhecimento da biodiversidade local e a etnoconservação da Caatinga.
\end{abstract}

Palavra-chave: Etnomicologla; Semlárido; Etnoconservaç̃o.

Perception of macrofungi in a caAtinga Rural community, northeast of Brazil

Aвstract - The perception of man about macrofungi occurs through colors, shapes and functionality, arousing curiosity and interest for them. Thus, the objective of this study was to understand how a rural community manifests the observed phenomena of known/ used macrofungi, based on their particular experiences and the maintenance of an intergenerational knowledge transmission. A semi-structured interview was used, accompanied by a serial photo album with 56 informants from Novo Zabelê community, followed by a guided tour. The perception relates to the appearance in the environment, seasonality, ludic and medicinal use, climatic condition and ecological function. The majority (91\%) reports the childhood as the beginning period of knowledge about fungi, where the family contributed to it through oral tradition regarding vernacular names and function in nature, being transmitted through generations, where negative perception was expressed by saying that they are harmful to health or are not useful, and the positive perception when its attribution becomes important for nature and use in popular medicine. The data reinforces that the fungi perception is constituted culturally and can contribute to the knowledge of the local biodiversity and the Caatinga ethno-conservation.

KeYwords: ETHNOMYCOLOGY; SEMI-ARID; ETHNO-CONSERVATION. 
Percepción sobre los macro hungos en una comunidad rural en la caAtinga, noreste del Brasil

RESumen - La percepción del hombre acerca de los macrohongos ocurre a través de los colores, las formas y la acción en el medio, despertando la curiosidad y el interés por ellos. De esa forma, se tuvo como objetivo comprender cómo una comunidad rural expresa los fenómenos observados de los macrohongos conocidos/ utilizados, con base en sus experiencias particulares y el mantenimiento del conocimiento por la transmisión intergeneracional de los saberes. Se utilizó la entrevista semiestructurada acompañada de álbum seriado de fotografías con 56 informantes de la comunidad de Novo Zabelê, seguida de visita guiada. La percepción está relacionada con el surgimiento en el ambiente, estacionalidad, utilización lúdica y medicinal, condición climática y función ecológica. La mayoría (91\%) representa la infancia como principio del conocimiento sobre los hongos, cuando la familia contribuyó para obtención de los saberes, por medio de la tradición oral acercade los nombres vernáculosy la función en la naturaleza, por transmisión entre generaciones, donde la percepción negativa se expresópor la afirmación de que hacen mala la salud o no son útiles, y la positiva con atribución de importancia para la naturaleza y el uso en la medicina popular. Los datos refuerzan que la percepción sobre los hongos está constituida culturalmente y pueden contribuir para el conocimiento de la biodiversidad local y la etnoconservación de la Caatinga.

Palabras clave: Etnomicología; SemLÁrido; Etnoconservación.

\section{INTRODUÇÃO}

$\mathrm{Na}$ história da humanidade, todo conhecimento sobre o mundo e sobre as coisas, tem estado condicionado pelo contexto geográfico, ecológico e cultural em que produz e reproduz uma determinada formação social, gerando formas de percepções (Leff 2010). Nesse sentido, busca-se compreender como a natureza é percebida pelos membros de grupos culturais distintos por meio do conhecimento sobre o meio ambiente (Rosa e Orey 2014).

É natural olharmos as belas paisagens e, observarmos as plantas, animais, rios, o homem que aí vive, mas, ignoramos as redes de fungos que sustentam esse espaço com seu importante papel decompositor de matéria orgânica. Isso porque os fungos têm função semelhante a atores coadjuvantes, executando ações fundamentais, porém, são poucos percebidos (Ishikawa et al. 2012). No entanto, o conhecimento das populações tradicionais suscita pensamento nas concepções ecológicas que podem contribuir para o conhecimento científico em aspectos particulares das florestas, como as interações ecológicas entre os organismos, como o caso entre fungos-plantas e fungos-animais (Vasco-Palágios et al. 2008).

Em comunidades rurais, por meio da cultura micófila, conseguem observar ambientes em que os fungos crescem, em decorrência da utilidade para o consumo e obtenção de renda, o que fazem perceberem dentre eles, os que são comestíveis e os venenosos (Ruan-Soto e Garibay-Orijel 2004; Ruan-Soto et al. 2009; Burrola-Aguilar et al. 2012). Em decorrência da utilização dos fungos por população micófila, comunidade da região do México atribuiu o aparecimento de certas espécies em tempo de chuva, fogo e apodrecimento da madeira, percebendo a origem do fungo, os substratos em que eles se desenvolvem, os tipos considerados comestíveis e os cogumelos venenosos, sendo que as diferentes formas de perceber os fungos estão ligadas a fatores históricos e culturais (Ruan-Soto et al. 2007).

$\mathrm{Na}$ relação homem e fungos é estabelecida percepção principalmente por meio de observação das cores e formatos dos fungos que despertam a curiosidade e estimulam aproximação com esses organismos (Amazonas e Siqueira 2003). No contexto dessa relação, não foram encontrados relatos do estudo de percepção de fungos 
ou da ação desses no ambiente na Caatinga do Nordeste brasileiro. Entende-se que a relação do homem com os macrofungos por meio da população local pode ser um instrumento que propicia direcionar uma série de discussão da biodiversidade local dentro de um contexto cultural. A falta do conhecimento sobre a relação das comunidades rurais nordestinas com os fungos pode deixar de registrar informações importantes relacionadas ao conhecimento tradicional e predição do clima, tão marcante para essa região, assim como conhecer as representações, crenças e valores por meio da utilização dos fungos.

$\mathrm{Na}$ perspectiva de relatar a representação dos elementos ambientais relacionada à realidade interna da mente dos indivíduos em relação à realidade externa (Silva e Albuquerque 2014), objetivou estudar percepções sobre macrofungos na comunidade Zabelê, visto que a mesma possui um processo histórico cultural bastante relevante e, por manter relação com uma Unidade de Conservação. Dessa forma, o trabalho tenta compreender como os moradores manifestam as percepções sobre os macrofungos conhecidos/usados, com base na cultura e suas experiências particulares e, como acontece a manutenção do conhecimento pela transmissão intergeracional dos saberes desses macrofungos.

\section{Metodologia}

O estudo foi desenvolvido na Comunidade Zabelê, localizada no município de São Raimundo Nonato, no sul do Piauí (Figura 1). O município possui uma população de 32.327 habitantes, com área territorial de 2.415,602 $\mathrm{km}^{2}$ e uma densidade demográfica de 13,38 hab $/ \mathrm{km}^{2}$ localizada na chapada das Mangabeiras, distante $530 \mathrm{~km}$ de Teresina, capital do Estado (IBGE, 2010). O clima da região é tropical semiárido quente, com duração do período de estiagem de sete a oito meses e a vegetação é típica de Caatinga arbórea e arbustiva (CEPRO, 2010).

Figura 1 - Mapa de localização da antiga e nova comunidade Zabelê, São Raimundo Nonato/PI.

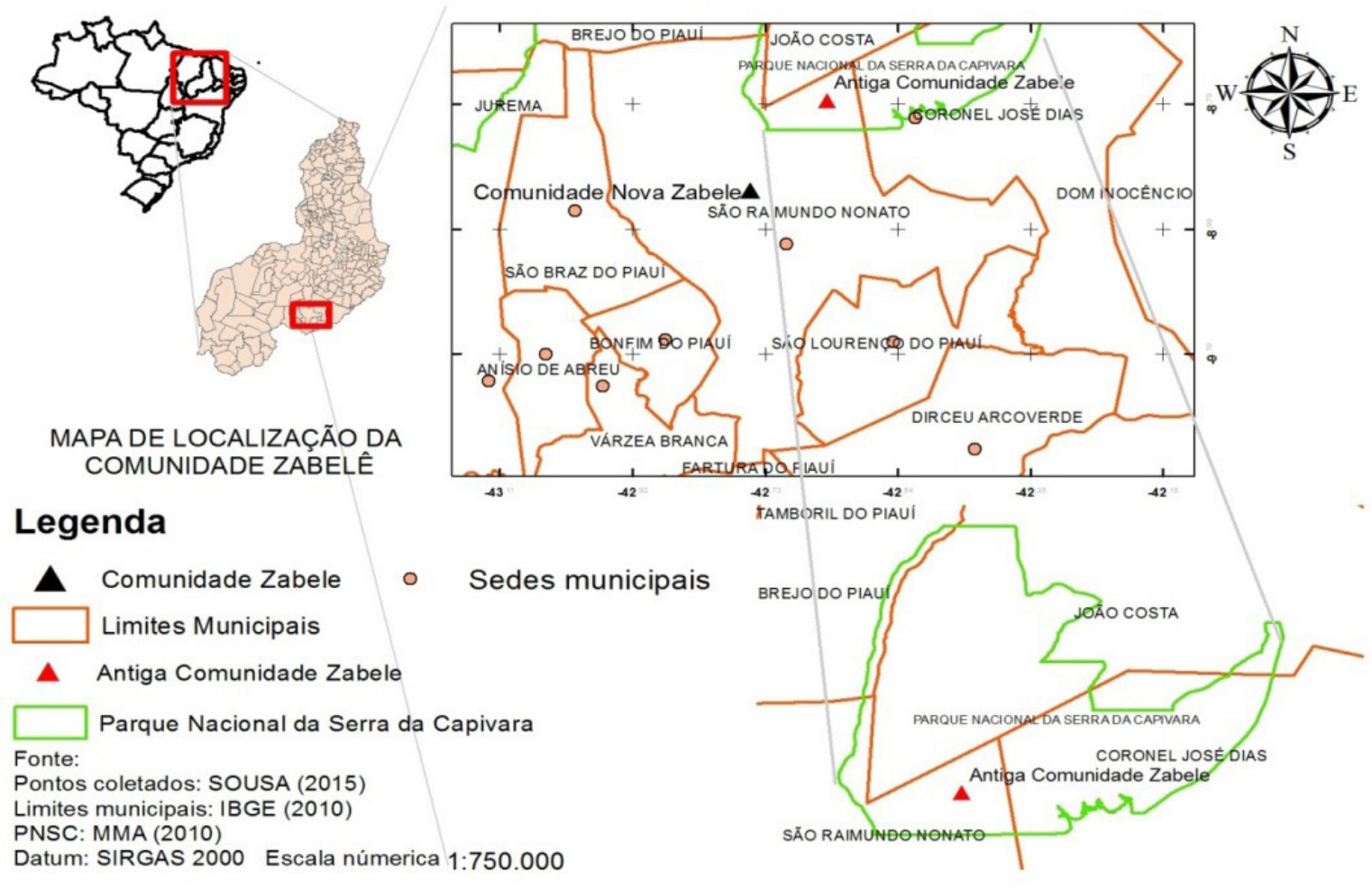


O processo de colonização da antiga comunidade Zabelê aconteceu de forma espontânea, localizando-se no entorno dos paredões da Serra da Capivara, teve como atrativo inicial o extrativismo da maniçoba (Manihot sp), distante 45 quilômetros da sede do município segundo Godoi (1999), onde sua constituição ocorreu por grupo social secular, formado entre os anos de 1800 e 1900, cujo território teve que ser desocupado pelas famílias que lá viviam devido à implantação do Parque Nacional Serra da Capivara, em 1989 (Matos 2012). Atualmente, está situada em assentamento rural denominado Nova Zabelê, criado através do Programa de Reforma Agrária do governo brasileiro, em 1997. Embora a comunidade tenha se deslocado, o cenário ambiental atual permanece o mesmo, ou seja, continua no mesmo bioma e com as mesmas condições ambientais.

Como o assentamento conta com pessoas vindas de toda a microrregião de São Raimundo Nonato, optouse por visitar todas as residências da comunidade nova Zabelê com finalidade de restringir o universo amostral somente com os moradores provenientes da antiga comunidade Zabelê, pressupondo que o conhecimento relativo aos macrofungos é mantido por transmissão intergeracional na comunidade. Considerando ainda, que os fatores históricos e culturais podem ser relevantes para o conhecimento da relação homem e fungos no bioma Caatinga. Dessa forma, foram entrevistadas 35 famílias, incluindo pelo menos um mantenedor (pai ou mãe) e um filho maior de 18 anos, perfazendo um total de 56 moradores com faixa etária de 19 a 90 anos, sendo 33 do gênero feminino e 23 do gênero masculino.

Este estudo foi aprovado pelo Comitê de Ética em Pesquisa (CEP) da Universidade Federal do Piauí (UFPI), com registro 36066214.4.0000.5214, atendendo ao que pressupõe a Resolução 466/2012 da Comissão Nacional de Ética e Pesquisa do Ministério da Saúde. A coleta de dados foi obtida com a utilização de entrevistas auxiliadas por formulário semiestruturado (Apolinário 2000), os quais concordaram em assinar o Termo de Consentimento Livre e Esclarecido (TCLE), no período de novembro de 2014 a março de 2015.

As entrevistas semiestruturadas sobre conhecimento de macrofungos seguiu-se com utilização projetiva de álbum seriado de fotografias (Medeiros et al. 2010) do qual foi confeccionado com espécies locais antes das entrevistas, realizando teste piloto com pessoas da comunidade, adequando uma melhor visualização, a fim de identificar os saberes etnomicológicos, por meio de registros do surgimento dos fungos no ambiente, sazonalidade, condições climáticas, utilização, e importância ecológica. O formulário utilizado nas entrevistas abordava também o perfil socioeconômico do informante. Seguiu-se com aplicação da técnica da "TurnêGuiada" preconizada por Bernard (1988), referida também por alguns autores como método informante de campo (Albuquerque et al. 2010), que consiste na realização de caminhadas no campo acompanhadas por moradores que possuíam maior conhecimento sobre o local e os macrofungos da região, em áreas da antiga Zabelê, localizada dentro do Parque Nacional Serra da Capivara e, na nova comunidade Zabelê Durante as turnês foram coletados exemplares do material fúngico, conforme procedimentos preconizados por VargasIsla, Cabral, Ishikawa (2014) e, Fidalgo, Bononi (1984). No Laboratório de Micologia da UFPI, identificou-se o material, por meio de observações macro e microscópicas, utilizando-se chaves analíticas contidas em literatura especializada e foi depositado na coleção de fungos do referido laboratório.

Os dados coletados foram organizados em tabelas e gráficos e analisados seguindo informações dos atores envolvidos na pesquisa, buscando comparar com bibliografias específicas. Para testar o conhecimento entre faixa etária, foi utilizado o programa STATISTICA 8.0.

Como critério de divisão dos grupos por faixa etária, seguiu-se a delimitação utilizada pelo Instituto Brasileiro de Geografia e Estatística (IBGE 2010): jovens (entre 18 e 24 anos), adultos (entre 25 e 59 ) e idosos 
(a partir dos 60).

\section{REsultados E Discussão}

O relato sobre os fungos percebidos pelos entrevistados está relacionado às observações no surgimento no ambiente: em plantas e no solo; sazonalidade: períodos de chuva ou de estiagem; condição climática: dia de sol ou de chuva; uso: lúdica e medicinal e, função ecológica: parasitismo e saprofitismo (decomposição orgânica).

As representações das percepções relatadas ocorreram quanto a utilidade e conhecimento dos macrofungos no ambiente. A forma de reconhecimento dos fungos por utilização é verificada em comunidades rurais que perceberam os fungos utilizados como alimentos e os venenosos nesse mesmo contexto e, está relacionada a fatores históricos e culturais da comunidade (Ruan-Soto et al. 2007).

Os fungos mais citados nas percepções dos informantes foram os que mantêm função ecológica na relação fungo-planta-ambiente, pertencentes à classe dos Basidiomycetes, das famílias Ganodermataceae, Polyporaceae e Agaricaceae. Sendo a família Ganodermataceae mais bem representada com gênero Ganoderma com destaque a dois complexos de espécies: complexo do Ganoderma applanatum (Pers.) Pat. e complexo do Ganoderma lucidum (W.Curt: Fr.) Krst., conhecidas popularmente como orelha-de-pau por crescerem sobre plantas que parasitam.

Com esse grupo de fungos, verificou-se que os entrevistados observam a relação fungos/plantas, detalhando característicos particulares. A percepção ambiental relatada pelos entrevistados foi validade pelos estudos de campo (Quadro 1).

Os relatos das percepções demonstram particularidades nas observações dos informantes presentes em cada categoria, conforme experiência verificada ambientalmente que são retratados por meio de uma visão holística. Em outros ecossistemas já foram relatados resultados de percepções dos fungos conhecidos e utilizados dentro do conhecimento tradicional, retratando pensamento integrador e holístico das relações ecológicas dos fungos com as plantas (Vasco-Palágio et al. 2008; Ruan-Soto 2007; Ruan-Soto et al. 2004).

Diante da percepção ambiental dos fungos, os informantes relataram importância por meio das observações verificadas percebidas. Assim, 65\% atribuem importância para natureza, relatando possuir algumas funções, dentre elas como controladores da natureza. Essa visão de "controladores da natureza" pode ser interpretada como a função ecológica dos fungos, sendo extremamente importante para manutenção da vida na terra, agindo como decompositores, reciclando a matéria orgânica tão necessária à continuidade da vida quanto os produtores de alimentos - sintetizadores (Fidalgo e Bononi 1984; Alexopoulos, Mims e Blackwell 1996; Raven, Evert e Eichorn 2001; Ishikawa et al. 2012).

Os informantes foram conduzidos a responderem em que fase da vida passou a perceber os macrofungos e de que forma. A maioria (91\%) se referiu à fase da infância, como primeiro momento de reconhecimento dos macrofungos, seguido da adolescência $(7 \%)$ e da fase adulta $(2 \%)$.

A fase da infância retratada pela maioria dos informantes é semelhante ao observado em alguns estudos de Etnoentomologia, em que os primeiros contatos com insetos ocorreram na infância, sendo repassado principalmente por pessoas da família (Lopes et al. 2014; Almeida Neto 2015). Assim, o contexto cultural é relevante na origem da informação para comunidade pesquisada, visto que a maioria teve o núcleo familiar como fonte primária no repasse do conhecimento como demonstrado na Figura 2. 
Quadro 1 - Percepção ambiental dos informantes na relação fungo-planta-ambiente.

\begin{tabular}{|c|c|}
\hline Percepção & Relatos \\
\hline Parasitismo & $\begin{array}{l}\text { "Porque adoece a planta (E } 59 \text { anos); "Mata a planta, se sair demais" (E } \\
73 \text { anos); "Quando a orelha aparece, a planta está enfraquecendo" (E } 64 \\
\text { anos); "Quando a orelha-de-pau aparece, a planta está condenada a mor- } \\
\text { te" (E } 49 \text { anos); "Quando cria muito, mata a planta" (E } 76,55 \text { anos); } \\
\text { Quando dá no tronco, a planta morre (E } 76 \text { anos); "onde a orelha-de-pau } \\
\text { nasce a planta morre" (E } 76 \text { anos). "O Chapeu-de-sol fofa a planta e } \\
\text { mata". (E } 52 \text { anos) "A planta ta pra morrer porque ta criando orelha-de- } \\
\text {-pau" (E } 61 \text { anos); "Quando o pau quer morrer, nasce a orelha" (E } 78 \\
\text { anos); "Quando uma planta chega no fim, solta a orelha-de-pau ..." (E } 37 \\
\text { anos). }\end{array}$ \\
\hline $\begin{array}{l}\text { Sazonalidade } \\
\text { (Mudança de estação) }\end{array}$ & $\begin{array}{l}\text { "Quando a orelha de pau está muchando, o inverno esta acabando" (E } 74 \\
\text { anos). }\end{array}$ \\
\hline Saprofitismo & $\begin{array}{l}\text { "Eles surgem em planta morta" ( E } 57 \text { anos), "a orelha-de-pau aparece em } \\
\text { tronco de pau que está morrendo ou morto" (E } 45 \text { anos); "A orelha-de-pau } \\
\text { aparece mais na planta que está morrendo" (E } 64 \text { anos). }\end{array}$ \\
\hline Ambiente & $\begin{array}{l}\text { "Não aparece em plantas que cultiva, aparece nas plantas nativas" (E } 68 \\
\text { anos) "Quando a orelha dá no tronco, a planta vai morrer; quando dá na } \\
\text { metade a parte de cima morre", "encontra em local aberto e não em mata } \\
\text { fechada, porque recebe mais sol" (E } 62 \text { anos). "A mãe dizia que era coisa } \\
\text { da terra" (E } 63 \text { anos). }\end{array}$ \\
\hline $\begin{array}{l}\text { Condição climática } \\
\text { (Temporal breve) }\end{array}$ & $\begin{array}{l}\text { "Quando chovia muito e o chapéu aparecia era sinal que o sol ia abrir" (E } 76 \\
\text { anos), "quando o chapéu de sol sai, a chuva suspende" (E } 64 \text { anos). }\end{array}$ \\
\hline Utilização Lúdica & $\begin{array}{l}\text { "deixar de brincar porque pode dar micróbio"(E } 73 \text { anos), "os mais velhos } \\
\text { diziam que não era para brincar com a bufa do cão porque o pó pode cair na } \\
\text { boca ou no olho e pode fazer mal" (E } 71 \text { anos). }\end{array}$ \\
\hline Utilização medicinal & $\begin{array}{l}\text { "O cogumel do sol serve para remédio" (E } 20 \text { anos). "A orelha-de-pau era } \\
\text { boa para fazer remédio" (E } 50 \text { anos). A orelha-de-pau serve para fazer chá, } \\
\text { a bufa-do-cão não serve" (E } 78 \text { anos). }\end{array}$ \\
\hline Toxidade & $\begin{array}{l}\text { "Não podia comer porque mata" (E } 51 \text { anos), "não pegar porque é veneno- } \\
\text { so" (E } 54 \text { anos, E } 68 \text { anos), "não podia botar na boca porque tem veneno" } \\
\text { (E } 44 \text { anos), "os mais velhos falavam que tem veneno" ( E } 56 \text { anos); } \\
\text { "quando saia com meus pais para a roça, eles diziam que não era para não } \\
\text { mexer porque podia fazer mal" (E } 32 \text { anos), "não podia pegar porque faz. } \\
\text { mal" (E } 19 \text { anos). }\end{array}$ \\
\hline
\end{tabular}

O núcleo familiar, representado pelos pais, avôs e tios, foi mais citado no repasse dos saberes, transmitindo conhecimento que tem influência perceptiva que vai desde os aspectos positivos aos negativos. Surge, pois, que o conhecimento sobre os macrofungos acontece nos primeiros contatos na infância, por citações da família, 
configurando, desse modo, a transmissão intergeracional dos saberes sobre macrofungos na comunidade. Membros mais velhos do grupo social que não sejam da família também foram citados como atores no repasse de informações. A aquisição do conhecimento também teve influencia exógena ao núcleo familiar, como o caso da escola, o qual contribuiu positivamente na aquisição do saber.

Figura 2 - Relação intergeracional na transmissão dos saberes sobre os macrofungos, citados pelos informantes da Comunidade Nova Zabelê, São Raimundo Nonato, Brasil.

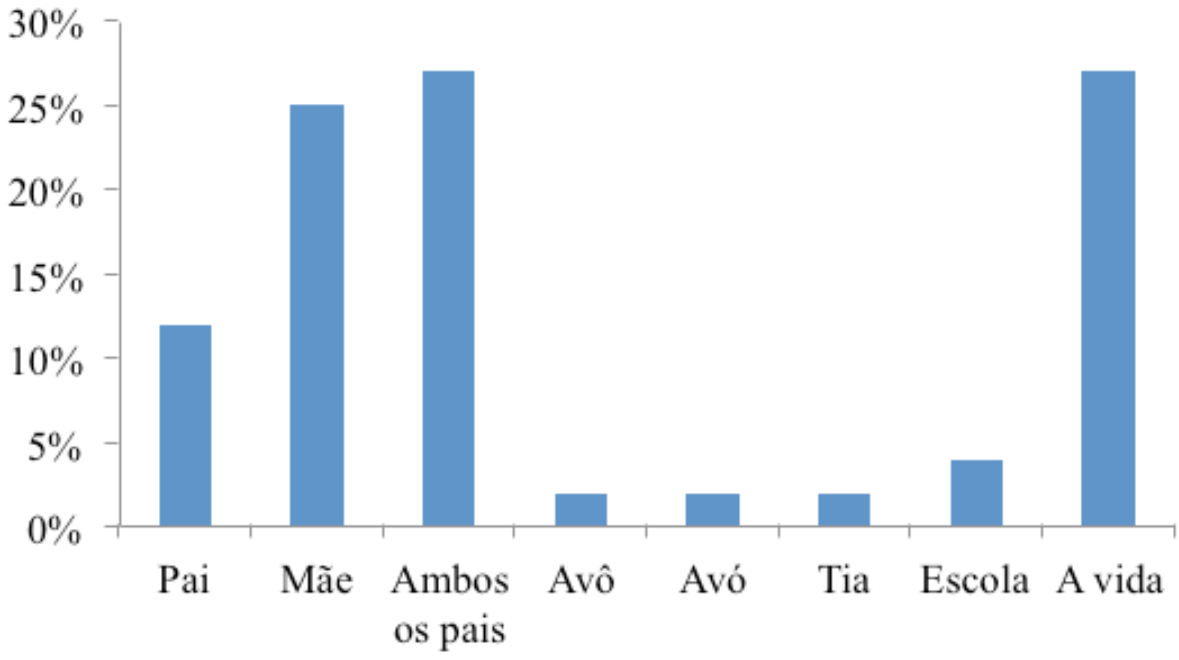

A transmissão de saberes na mesma geração, entre irmãos e primos, não foi citada, no entanto, percebese que a aquisição de conhecimento através de experiências "da vida" representa uma forma de construção cognitiva importante. Nesse sentido, Soldati (2013) reforça que essas observações particulares são positivas, pois apresentam característica que pode incorporar constantemente os dados disponíveis no meio ambiente por meio de cognição.

Dentre o repasse das informações, foi observado ocorrência de percepção negativa com o grupo de macrofungos dos gêneros Leucocoprinus s e Podaxis pistilares, observados no período de chuva. O Leucocoprinus foi retratado em memórias da infância, quando eram usados como ingrediente de fazer comida quando brincava de cozinhar e, com o Podaxis pistilares se divertiam, chutando os cogumelos que encontravam no caminho. Brincar com os fungos já foi registrado no estudo de Ruan-Soto et al. (2009) com espécies Cookeina sulcipes e C. tricholoma em comunidade do México onde pegava o cogumelo e soprava no copo, em seguida, colocava a orelha para ouvir sons de vento.

Os informantes relataram que quando brincavam, membros da família falava que "não podia comer porque mata" (E 51 anos), "deixar de brincar porque pode dar micróbio" (E 73 anos), "não pegar porque é venenoso" (E 54 anos, E 68 anos), "os mais velhos diziam que não era para brincar com a bufa do cão porque o pó pode cair na boca ou no olho e pode fazer mal" (E 71 anos), "não podia botar na boca porque tem veneno" (E 44 anos), "os mais velhos falavam que tem veneno" (E 56 anos); “quando saia com os pais para a roça, eles diz̨iam que não era para não mexer porque podia fazer mal” (E 32 anos), “não podia pegar" (E 19 anos). A representação negativa com os macrofungos tem certa semelhança com estudos de percepções na etnoentomologia em comunidades rurais quanto a conceituação de insetos, causadores de ofensas e injúrias, gerando desconfortos emocionais, registrado no trabalho de Almeida Neto et al. (2015).

A relação com eventos climáticos também foi percebido pela comunidade, o que era esperado na visão do sertanejo que, ao longo dos anos vem procurando compreender eventos climáticos através dos elementos 
da natureza. Assim, plantas e animais podem apresentar características que são interpretadas como previsões ou sinais nas crenças populares durante os meses de verão e inverno no sertão brasileiro. Para os sertanejos, verão e inverno correspondem ao tempo de estiagem e chuvoso respectivamente. Os sinais podem representar inverno intenso ou suspensão de chuva. Isso é uma prática entre os sertanejos, que tanto sofrem com a seca, observam a natureza para dela buscar explicações nos fenômenos naturais (Galeno 1998, Folhes e Donald 2007; Pennesi e Souza 2012). Entre os animais, muitos insetos são profetizadores como observado em comunidade rural no estado do Piaú, sinalizando a presença ou ausência de chuva ou do inverno (Almeida Neto et al. 2015). Os fungos foram citados nas previsões dos entrevistados em três relatados, apontando esses organismos como sinais que revelam tempo e clima. Dentre os relatos aparecem "Quando chovia muito e o chapéu aparecia era sinal que o sol ia abrir" (E 76 anos), "quando o chapéu de sol sai, a chuva suspende" (E 64 anos), "quando a orelha de pau está muchando, o inverno esta acabando" (E 74 anos).

Foi analisada como os informantes atribuem importância aos macrofungos. Dentre as respostas, houve relatos de forma negativa e positiva entre todas as faixas etária. A percepção negativa ocorreu por meio de que fazem mal ou não são utilizados. No aspecto positivo é referenciada por ser útil em algum aspecto (Figura 4).

Figura 3 - Histograma da categorização das variáveis quanto à faixa etária da importância dada aos macrofungos, citados pelos informantes da Comunidade Novo Zabelê, São Raimundo Nonato, Brasil, utilizando o programa do STATISTA 8.0.
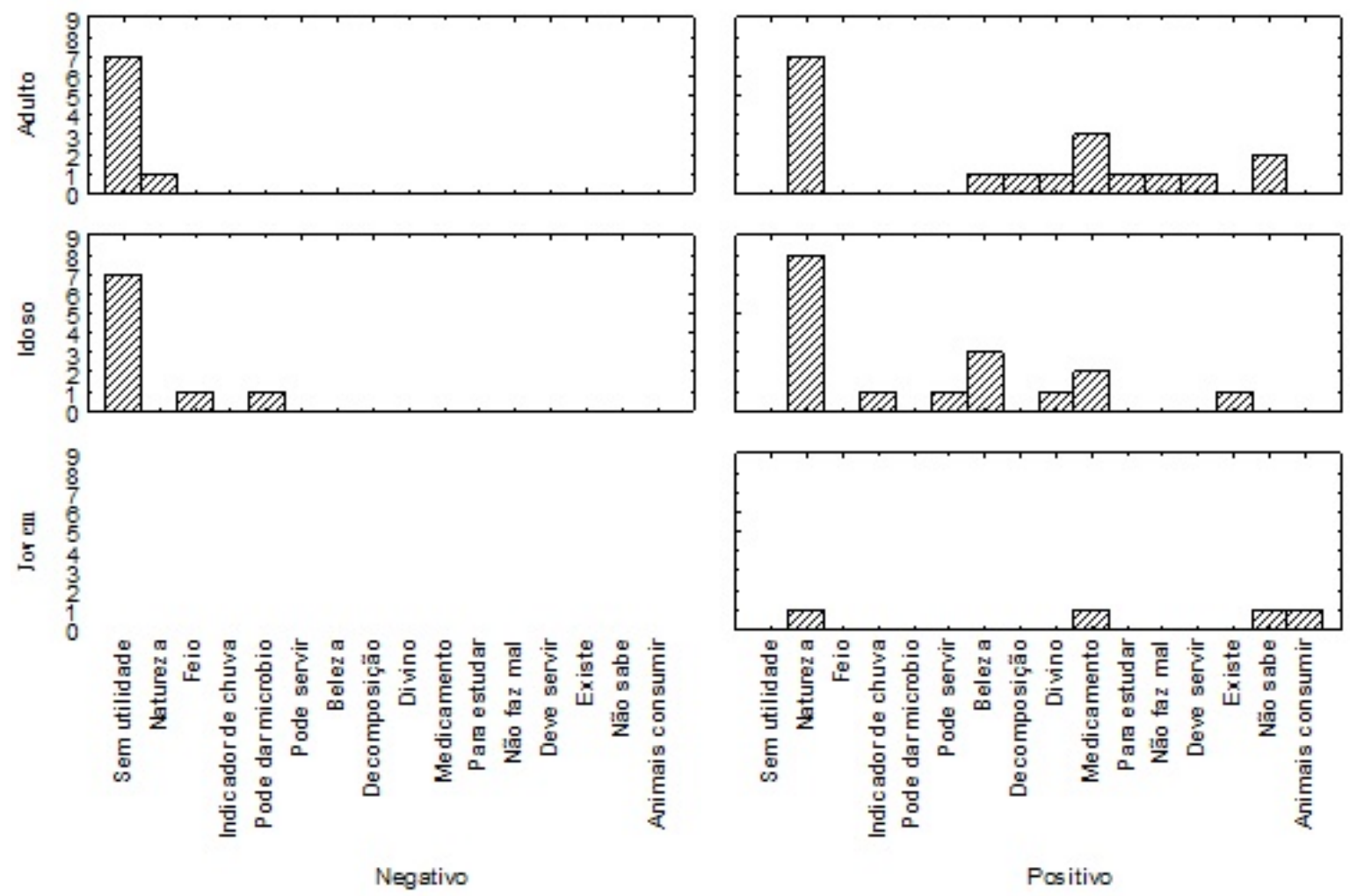

A representação negativa nas variáveis de faixa etária é observada nos adultos e idosos, atribuições quanto à percepção principalmente por não apresentarem uso. No aspecto positivo, percebe-se que entre idosos, adultos e jovens há um consenso de utilidade para a natureza e na medicina popular. O aspecto positivo e negativo foi caracterizado no contexto de sentimento ambíguo da população pesquisada, observado na citação "eles são importantes, mas é preguiçoso porque precisa matar os outros para viver"' (E 62 anos). A atribuição utilitária reforça a ideia que o homem, através de suas observações, apreende conhecimento detalhado sobre determinados seres vivos a partir de sua utilização e, são passada de geração em geração (Begossi 1993) e, constitui em processo oral de 
transmissão do conhecimento por parte de populações tradicionais (Pereira e Diegues 2010). Houve aquisição do conhecimento na faixa etária jovem no aspecto positivo, diferenciando dos adultos e idosos, quando afirma que espécies de macrofungos são importantes porque "os animais consomem” (E 22 anos), atribuindo uso para espécies de cogumelos, demonstrando que esses organismos participam da cadeia alimentar dos animais.

Durante as entrevistas, observou-se que as representações citadas estão ligadas a atividade agrícola e esta, é transmitida oralmente entre gerações e, por construção cognitiva. Esse fato é recorrente mesmo entre os informantes jovens que possuem escolaridade mais avançada, como descrito nas citações "quando andava na roça com minha mãe e meu avô eles falavam o nome e diziam que era para não pegar" (E 19 anos), "andando na roça o pai e a mãe diæia o que era" ( E 64 anos) " quando via na roça e quando ia pegar lenha” (E 71 anos). O resultado demonstra que a transmissão do saber por parte dos membros familiares tem forte influencia no conhecimento sobre os macrofungos o que viabiliza fonte de obtenção de dados para projetos de levantamento da biodiversidade e etnoconservação, sobretudo com espécies lúdicas citadas, onde a maioria dos entrevistados demonstrou atitudes não conservacionistas, o que poderia desenvolver atividades de Educação Ambiental para com esse grupo de seres vivos.

\section{ConClusão}

De acordo com as informações obtidas, sugere-se que há necessidade de mais estudos do conhecimento popular com os macrofungos, principalmente em áreas de Caatinga no estado do Piaú, para verificar se a metodologia usada e os relatos de percepção encontrados na comunidade Zabelê são semelhantes em outras comunidades rurais, visto que o trabalho é pioneiro no estudo etnomicológico realizado no estado. Esses achados podem ser importantes para etnoconservação da Caatinga por viabilizar a visão do sertanejo no papel que desempenha os macrofungos na natureza.

Sugere-se que o conhecimento etnomicológico da comunidade Zabelê seja considerado em projetos desenvolvidos no Parque Nacional Serra da Capivara para que sejam mantidos os saberes ao longo das gerações e assim, valorizar o conhecimento local nas ações de educação ambiental do PARNA (Parque Nacional Serra da Capivara). A população pesquisada, embora não descreva de forma clara, demonstram que não são micófobas.

\section{REFERÊNCIAS}

Albuquerque UP, Lucena FPR, Alencar LN. 2010. Métodos e Técnicas para coleta de dados etnobiológicos. In: Albuquerque U P, Lucena R F P, Cunha L V F.C. 2010. (Orgs). Métodos e Técnicas na pesquisa Etnobiológica e Etnoecológica. Recife-PE: NUPEEA, 41-63 p.

Alexopoulos CJ, Mims C W, Blackwell M. Introductory Mycology. 1996. New York, 865 p.

Almeida Neto JR, Costa Neto E M, Silva P R R, Barros, R F M. 2015. Percepções sobre insetos em duas comunidades rurais da Serra do Passa Tempo, Nordeste do Brasil. Revista Espacios , vol. 36, n.11.

Amazonas MAL, Siqueira P. 2003. Champignon do Brasil (Agaricus brasiliensis): Ciência, Saúde e Sabor, 
Colombo: Embrapa Florestas, 45 p.

Begossi A. 1993. Ecologia Humana: um enfoque das relações homem-Ambiente, Interciência, vol. 18, n. 1, pp. 121-132.

Burrola-Aguilar C; Montiell O, Garibay-Orijel R, Zizumbo-Villarreal L. 2012. Conocimiento tradicional y aprovechamiento de los hongos comestibles silvestres em la región de Amanalco, Estado de México. Revista Mexicana de Micologia, v.35.

CEPRO - Fundação Centro de Pesquisas. 2010. Perfil dos municípios, Teresina: Fundação CEPRO.

Fidalgo O, Bononi V L R. 2007. Técnicas de coleta, preservação e herborização de material botânico. Instituto de Botânica, São Paulo no 4, 62 p.

Folhes MT, Donald N. 2007 Previsão tradicional de tempo e clima no Ceará: o conhecimento popular a serviço da ciência. Sociedade \& Natureza, Uberlândia, vol.19 n.2, pp.19-31.

Galeno AS. 1998. Seca e inverno “experiências” dos matutos. Fortaleza: Coopcultura, 97 p.

Godoi PE. 1999. O trabalho da memória: cotidiano e história no sertão do Piauí. Campinas, SP: Unicamp, $55 \mathrm{p}$.

IBGE (Instituto Brasileiro de Geografia e Estatística). 2010. Aspectos físicos de São Raimundo Nonato. Disponível em: <http://www.ibge.gov.br/cidadesat/topwindow.htm?1>. Acesso em: 10 ago. 2014

Ishikawa NK, Vargas-Isla R, Chaves R S, Cabral T S. 2102. Macrofungos da Amazônia: importância e potencialidades. Ciência \& Ambiente, vol.44, pp.129-139.

Leff E. 2010. Epistomologia Ambiental. Cortez, São Paulo,5. Ed, 239 p.

Lopes PP, Franco I L, Oliveira L R M, Reis V G R. 2013. "Insetos na escola: desvendando o mundo dos insetos para as crianças”, Revista Ciência em Extensão, vol.9, n.3, pp.125-134.

Matos TCC. 2012. Imperativos político-normativos da política ambiental e da reforma agrária: impactos da comunidade Zabelê. In: XV ENCONTRO DE CIÊNCIAS SOCIAIS DO NORTE E NORDESTE e PRÉALAS BRASIL, 2012,Teresina-PI/Brasil. Anais... Teresina.

Medeiros PM, Almeida A L S, Lucena R F P, Souto F J B, Albuquerque U P O. 2010. O uso de estímulos visuais em Pesquisa etnobiológico. 2010. In: Albuquerque UP; Lucena RFP; Cunha LVFC (Org). Métodos e Técnicas em Etnobiologia e Etnoecologia. Recife-PE: NUPEEA, 558 p.

Pennesi K, Souza CRB. 2012. O encontro anual dos profetas da chuva em Quixadá, Ceará: a circulação de discursos na invenção de uma tradição. Horizontes antropológicos, Porto Alegre, vol.18 n.38.

Pereira BE, Diegues AC. 2010. Conhecimento de populações tradicionais como possibilidade de conservação da natureza: uma reflexão sobre a perspectiva da etnoconservação. Desenvolvimento e Meio Ambiente, n. 22 , pp. 37-50. 
Raven PH, Evert RF, Eichorn SE. 2001. Biologia Vegetal. Ed. Guanabara Koogan S.A,874.

Rosa M, Orey DC. 2014. Aproximando diferentes campos de conhecimento em educação: a etnomatemática, a etnobiologia e a etnoecologia. Vidya, v. 34, n. 1, pp.1- 14.

Ruan-Soto F, Garibay-Orijel R, Joaquim C. 2004. Conocimiento micológico tradicional em la planície costera del Golfo de México. Revista Mexicana de Micologia, v. 19, pp. 57-70.

Ruan-Soto F, Marianca MR, Cifuentes J, Aguirre LF, Pérrez-Ramírez L, Sierra-Galván S. 2007. Nomenclatura, classificación y percepciones local es acerca de los hongos em dos comunidades de La selva Lacandona, Chiapas, México. Etnobiología, vol.5, pp.1-20.

Ruan-Soto F, Cifuentes J, Marianca M R, Limon F, Pérez-Ramiry L, Sierra S. 2009. Uso y manejo de hongos silvestres em dos cumnidades de la Selva Lacadona, Chiapas, México. Revista Mexicana Micologia, v.29.

Silva TC, Albuquerque UP. 2014. O que é percepção ambiental? In: Albuquerque U P. Introdução à Etnobiologia. Recife-PE: NUPEEA, 55-58 p.

Soldati GT. 2013. Transmissão de conhecimento: origem social das informações e da evolução cultural. In: Albuquerque, U.P. (org.) Etnobiologia: bases ecológicas e evolutivas. Recife, PE: NUPEEA, 37 - 51p.

Vasco-Palacios AM, Suaza SC, Castaño-Betancur M, Franco-Molano A E. 2008. Conhecimento etnoecológico de fungos entre os indígenas Uitoto, Muinane e Andoke da Amazônia Colombiana. Acta Amazônica, vol.38, n.1, pp. 17-30.

Vargas-Isla R, Cabral T S, Ishikawa N K. 2014. Instruções de coleta de macrofungos Agaricales e gateroides. INPA, Manaus, 30p. 